\title{
Energias renováveis e sua eficiência na nova economia energética no Brasil
}

\section{Ana Cândida Ferreira Vieira}

Universidade Federal da Paraíba. Centro de Ciências Aplicadas e Educação. Departamento de Ciências Sociais Aplicadas. Campus IV. Litoral Norte. Mamanguape-PB, Brasil (CEP 58280-000). E-mail: acandidafv@yahoo.com.br.

Resumo. As necessidades de produção e crescimento econômico exigem das Nações o uso intensivo de energias para mover o processo produtivo, que pela suas dinâmicas não é estática em meio ao ciclo produtivo. 0 pensar da Ciência como geração de energia faz-se no início do crescimento econômico das nações, através da sua utilidade extraída da lenha, do carvão, do petróleo, dentre outros, proporcionando o uso de energia suja ou não renovável em meio a produção, que contribuiu com a emissão de poluição e aquecimento do planeta. Discussões e debates proporcionaram reuniões e conferências que tentam dispertar em gestores das Nações a repensar na mudança do uso de energia suja pela energia limpa, ou seja as renovável. Nesse contexto, o artigo tem o objetivo de observar a oferta e o consumo da energia renovável no mercado brasileiro, bem como seu avanço energético. Além de destacar alguns casos da eficiência da energia limpa no mundo. A metodologia é bibliográfica e documental, com estudo explicativo e descritivo. Justifica-se o artigo pela relavância de crescimento do mercado energético devido a troca de consumo pelas energias renováveis extraidas das forças que movem a natureza e o meio ambiente. Conclui-se que o próprio sistema de oferta e consumo de energias no mercado energético já impulsionaram as Nações a investirem na mudança da energia não renovável para renovável no sistema econômico e social, mostrando a necessidade de uso de energia para contribuir com a redução do aquecimento da Terra, conservar a natureza e crescer economicamente com sustentabilidade.

Palavras-chave: Energias renováveis; Mercado energético; Brasil.

Abstract. Renewable energies and its efficiency in the new energy economy in Brazil. The needs for production and economic growth require nations to use energy intensively to move the production process, which due to its dynamics is not static in the middle of the production cycle. The thinking of Science as energy generation takes place at the beginning of the economic growth of nations, through the utility of energy extracted from firewood, coal, oil, among others, providing the use of dirty or non-renewable energy, which contributed to the
Recebido

$05 / 08 / 2020$

Aceito

$10 / 04 / 2021$

Disponível on line

$12 / 04 / 2021$

Publicado

$30 / 04 / 2021$

Acesso aberto

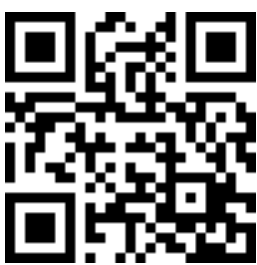

ORCID

(D) 0000-0001-5845-6519 Ana Cândida Ferreira Vieira

ISSN 2359-1412/RBGAS-2020-0120/2021/8/18/13/211

Rev. Bras. Gest. Amb. Sustent.

http://revista.ecogestaobrasil.net 
emission pollution and global warming. Discussions and debates provided meetings and conferences that try to awaken in managers of the Nations to rethink in the change of the use of dirty energy for the clean energy, that is to say the renewable ones. The article aims to observe the supply and consumption of renewable energy in the Brazilian market, in addition to highlighting some cases the efficiency of clean energy in the world. The methodology is bibliographic and documentary, with explanatory and descriptive study. The article is justified by the relevance of growth in the energy market due to the exchange of consumption for renewable energies extracted from the forces that move nature and the environment. The conclusion of the study shows that the system itself of supply and consumption of energy in the energy market has already directed the Nations to invest in the change from non-renewable to renewable energy in the economic and social system, showing the need to use energy to reduce the warming of the Earth and conserve nature and grow economically with sustainability.

Keywords: Renewable energy; Energy market; Brazil.

\section{Introdução}

A constituição dos elementos naturais no planeta através dos seus movimentos ressaltam de anos remotos, que proporcionaram auxílio para a realização de estudos e pesquisas que possibilitaram o domínio do fogo, o surgimento da roda, as máquinas e os equipamentos, cujo propósito era os mecanismos para impulsionar a força física e facilitar o transporte (Gidenns, 2010). Descobriram a força das águas, dos ventos, do sol e da terra, o tempo foi passando e relacionando a história da energia surgiram as máquinas a vapor, muito presente na Revolução Industrial do século XVIII.

Gidenns (2010, p.164) destaca que "o pensador político norte-americano Jeremy Rifkin afirma que as grandes mudanças da história mundial ocorreram quando novas fontes de energia surgiram simultaneamente a avanços nas comunicações". Nesse contexto, a primeira Revolução Industrial do século XVIII, necessitou da convergência entre a energia baseada no carvão, que possibilitou transformações no âmbito das forças produtivas da economia (Brum, 2013)

Com a expansão do crescimento econômico entre as nações, o sistema capitalista na busca da dinâmica pelo lucro foi cada vez mais passando por transformações, avanços técnicos e tecnológicos, agilidades, rapidez e inteligência, até artificial.

A "Segunda Revolução Industrial" teve início no final do século XIX. Foi marcada pela invenção da comunicação elétrica, começando com o telégrafo e se ramificando pelo telefone, o rádio e a televisão. Esses avanços convergiram para o surgimento do petróleo como a principal forma de geração de energia e como a fonte dominante de energia para os transportes.

Agora, no que dizer de Rifkin, estamos à beira de uma "Terceira Revolução Industrial", que terá como pano de fundo o desenvolvimento das comunicações em redes, representadas pelos computadores pessoais e pela internet. 0 potencial dessas tecnologias encontra-se em sua convergência com fonte renováveis de energia (Gidenns, 2010, p. 164). 
As energias renováveis surgem como saída e com alternativas de viver bem na inter-relação com o sistema econômico como um todo, além da necessidade de substituir a energia suja (não renovável) pela energia limpa (renovável) sem proporcionar uma redução do crescimento econômico, e sim em agregar alternativas para crescer, desenvolver e sustentar a economia, o social e o ambiental simultaneamente.

Com base no contexto do estudo de energias renováveis surgiu a seguinte indagação: como a eficiência energética das energias renováveis proporcionam a oferta no mercado brasileiro?

0 presente estudo tem como objetivo geral mostrar a eficiência e expansão da energia renovável no mercado brasileiro, em um contexto atual, destacando seu desempenho na nova economia energética através de alguns casos no país e no mundo.

\section{Natureza, tecnologias renováveis e geração de energias}

A palavra tecnologia vem da origem do grego tekhne que significa técnica, arte, ofício" juntamente com o sufixo logia que significa estudo de algo (Oliveira, 2008). Logo, tecnologia é a técnica de algo e esta é utilizada para a geração de energias renováveis, que são extraídas da natureza de fontes como luz solar, vento, chuva, maré, ondas e calor geotérmico, que ao serem agregadas as tecnologias geram as energias limpas, conhecidas como renováveis (Lovins e Cohen, 2013).

Conforme Gidenns (2010, p. 164), "tem havido tentativas ambiciosas de prever de que modo a disseminação das tecnologias renováveis transformará as economias modernas. Alguns falam do advento de uma nova Revolução Industrial, que seria iniciada por essas tecnologias". Atualmente, as energia renováveis de fontes da natureza e processadas pelas tecnologias estão destacadas no organograma da Figura 1.

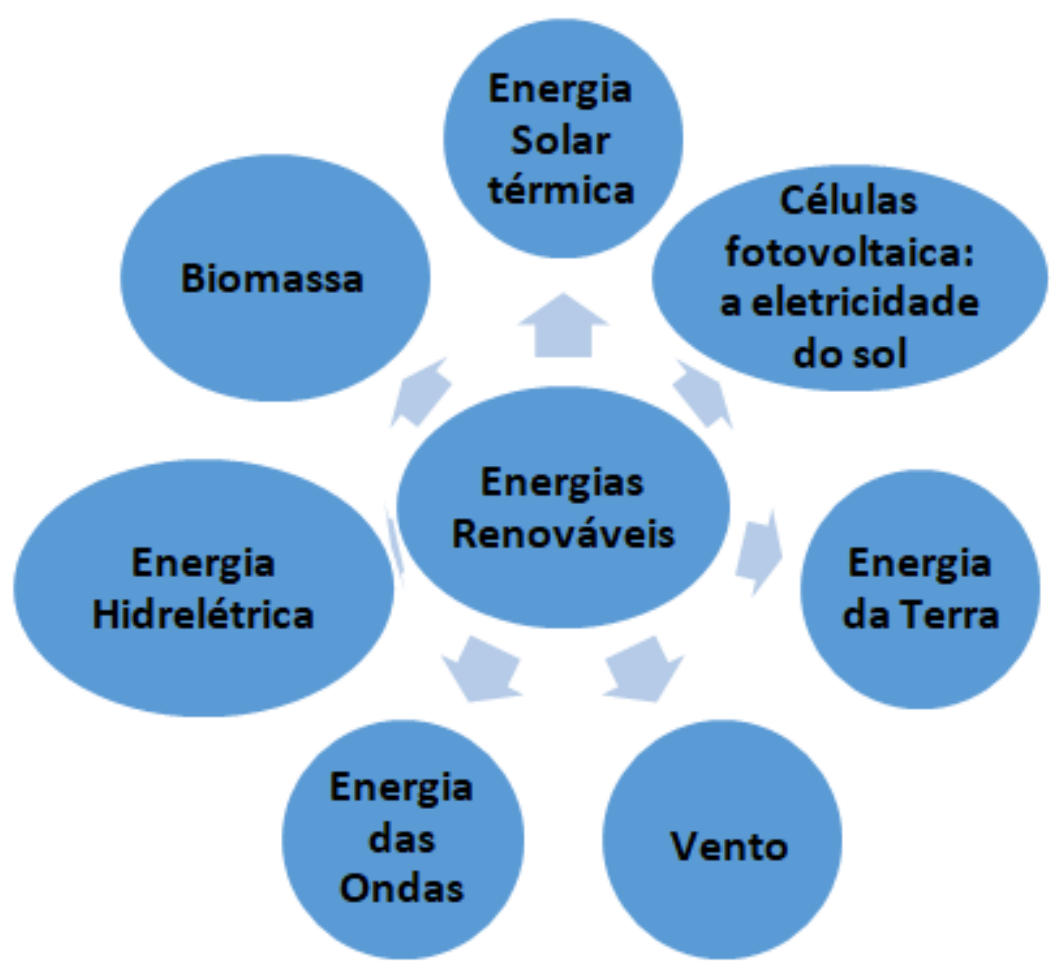

Figura 1. Tipos energias renováveis no mundo. Fonte: Lovins e Cohen (2013, p. 75-90). 
Cada elemento da natureza, destacado na Figura 1, possibilita uma maneira particular de transformar os movimentos em energias através da ciência com o uso da tecnologia. Como por exemplo a energia solar térmica que utiliza o calor do sol para aquecer prédios ou a água, além de fornece calor para processos industriais e produzir eletricidade.

Solar thermal heating and cooling systems served millions of residential, commercial, industrial and public clients in 2019. By year's end, the systems had been sold in at least 134 countries for use in a wide range of applications including hot water, space heating and cooling, product drying and water desalination.

An estimated 31.3 gigawatts-thermal (GWth) of glazed (includingflat plate and vacuum tube technology) and unglazed solar collectors was added globally in 2019, and by year's end a total of an estimated 479 GWth was in operation. These three types of solar thermal collectors provided around 389 terawatt-hours (TWh) $(1,402$ petajoules, PJ) of heat annually by the end of 2019 - equivalent to the energy content of 229 million barrels of oil (REN21, 2020, p. 124).

O calor do sol ainda ajuda nas Células fotovoltaicas, que tem como parte importante o silício, segundo Lovins e Cohen (2013) depois da eólica, a tecnologia mais rápida para produzir eletricidade a partir de fontes renováveis é a elétrica solar, que conforme o Departamento de Energia dos Estados Unidos calculou que a demanda de energia poderia ser inteiramente satisfeita cobrindo $9 \%$ do estado de Nevada, aproximadamente 238 quilômetros quadrados com painéis fotovoltaicos, que transformam a energia calorifica do sol em eletricidade de corrente direta, no entanto pagar por centrais elétricas centralizadas, de capital intensivo, que cobrem uma extensão de terras cultiváveis com painéis solares e depois pagar por linhas de transmissão para levar energia para as cidades de telhados planos onde é necessário, mas se as placas estiverem alocadas nos próprios telhados das casas e empresas é menos custo e mais vantajoso para algumas regiões.

In 2019 the solar PV market increased an estimated 12\% toaround 115 GWi.1 The decade ended with strong demand in Europe, the United States and emerging markets around the world, more than making up for a substantial decline in China, the single largest market.2 Not including China, the global Market for solar PV grew about $44 \%$ in 2019.3 The global total of $627 \mathrm{GW}$, which includes on- and offgrid capacity, compares to a total of less than $23 \mathrm{GW}$ only 10 years earlier (REN21, 2020, p. 107).

Além da energia extraídas do sol, existem também as vindas do vento que nos bons locais o vento agregado a modernas torres com turbinas de ventos podem gerar uma eletricidade através da energia eólica.

Wind power provides a substantial share of electricity in a growing number of countries. In 2019, wind energy generated enough to provide an estimated $15 \%$ of the EU's annual electricity consumption, and equal or higher shares in at least seven individual Member States. Wind energy met an estimated $47 \%$ of Denmark's electricity demand in 2019 and accounted for nearly 57\%i of the country's total generation.14 Other countries in Europe with Wind generation shares above 20\% for all of 2019 included Ireland (32\%), Portugal (26.4\%), Germany (21.8\%) and Spain (20.9\%).15 Uruguay (29.5\%), Nicaragua (17.4\%) and Costa Rica $(15.8 \%)$ also achieved high shares of generation from wind energy in 2019, and shares were high at the sub-national level in several countries.16 By year's end, wind power capacity in operation worldwide was enough to provide an estimated $5.9 \%$ of total global electricity generation (REN21, 2020, p. 132). 
Depois do sol e do vento, também é possível extrair da natureza a energia da Terra, conhecida como a geotérmica derivada da profundidade do interior da terra a temperatura do calor alto, pela intensidade que provêm do subsolo acoplada a técnica para transformar em energia com quantidades nas regiões possíveis. Sendo mais uma alternativa de energia renovável.

\begin{abstract}
A energia geotérmica derivada do calor da terra pode suprir energia de carga de base para complementar a energia fornecida pelas instalações eólicas e solares. A energia geotérmica pode ser vantajosa quanto ao custo onde quer que na terra a rocha quente e a água esteja a alguns quilômetros da superfície do planeta, e mais de 50 países hoje a utilizam. A Islândia, que já obtém $50 \%$ da sua energia de fontes geotérmicas, está agora apostando a sua economia nessa tecnologia (Lovins e Cohen, 2013, p. 85).
\end{abstract}

Além dessas possibilidades apresentadas de alternativas de energia existem a energia das ondas ou ondomotriz, que também despertou atenção da pesquisa pela força que exerce através do oceano. Conforme Lovins e Cohen (2013), a primeira fazenda comercial de ondas no mundo é a Aguçadoura, situada ao largo da costa de Portugal, esse projeto iniciou com 2,25 megawatts, mas planeja expandir para 20 megawatts e em 2050 pretendem chegar a gerar $30 \%$ de energia para Portugal.

A força das águas doce possibilitam a energia hidrelétrica, que corresponde ao aproveitamento de energia cinética contido no fluxo de massas de águas dos rios ou quedas d'águas, que adicionada a tecnologia e a construção civil possibilitam a geração de energia. São gigantescas construções que levam tempo e custos para a construção, mas através dela é possível um retorno viável econômico e financeiro ao longo do tempo. Conforme ANEEL (2008, p. 53).

A primeira hidrelétrica do mundo foi construída no final do século XIX - quando o carvão era o principal combustível e as pesquisas sobre petróleo ainda engatinhavam - junto às quedas d'água das Cataratas do Niágara. Até então, a energia hidráulica da região tinha sido utilizada apenas para a produção de energia mecânica. Na mesma época, e ainda no reinado de D. Pedro II, o Brasil construiu a primeira hidrelétrica, no município de Diamantina, utilizando as águas do Ribeirão do Inferno, afluente do rio Jequitinhonha, com 0,5 MW (megawatt) de potência e linha de transmissão de dois quilômetros (ANEEL, 2008, p. 53).

Além dos elementos da natureza proporcionarem a força para gerar energias, as matérias orgânicas também despertaram estudos que geraram técnicas e tecnologias para a transformação de energia. Nesse propósito surge a bioenergia extraída da biomassa, que corresponde a toda matéria orgânica de origem vegetal ou animal, como por exemplo uso de restos de madeira, bagaço de cana, lenha, carvão vegetal, dejetos de animais e outras fontes primárias de energia. A biomassa é obtida pelo processamento dos resíduos dessas matérias através de tecnologias desenvolvidas com particularidades para cada tipo de matéria utilizada na geração e cogeração de energia.

Bioenergy use for industrial heating has occurred mainly in countries that have large bio-based industries. Brazil, the largest user of biomass for industrial heat in 2018 (1.6 EJ), relies on sugarcane residue (bagasse) from sugar production to generate heat in CHP systems.18 India (1.4 EJ), also a major sugar producer, was the second largest user of bioenergy for industrial heat in 2018, followed by the United States (1.3 EJ), which has na important pulp and paper industry (REN21, 2020, p. 83). 
Em uma visão geral da ciência com os elementos da natureza e a tecnologia relacionada é possível observar a grandeza das pesquisas na busca de alternativas para gerar energia sem emitir poluição ou até degradação. E como o sistema econômico é movido pela troca entre os agentes (empresas particulares e públicas, família, governo e agentes internacionais) envolvidos no sistema econômico, surge o mercado de energias renováveis.

\title{
Energia renovável na nova economia energética
}

As descobertas e o avanço da pesquisa e dos estudos possibilitaram uma evolução na economia de cada nação, que agregadas proporcionam toda a movimentação do sistema econômico global, chegando a influenciar no social e ambiental de cada nação.

Gidenns (2010, p. 164) afirma que "podemos imaginar uma economia energética mundial em que milhões de pessoas produzirão energia renovável e a compartilharão com outras, por meio de redes elétricas nacionais e internacionais - como hoje acontece com as informações".

\begin{abstract}
Mundialmente, os investimentos no mercado de projetos de energia renovável poderão chegar a 50 bilhões de dólares em 2011, com taxas de crescimento anual de dois dígitos. As Nações Unidas descreveram "uma corrida do ouro de novos investimentos em energia renovável", concluindo que a energia limpa poderia fornecer quase um quarto da eletricidade do mundo em 2030. 0 Conselho Europeu de Energia Renovável se mostrou ainda mais otimista, afirmando que 50\% do suprimento de energia do mundo poderá vir de fontes de energia renovável até 2040 (Lovins e Cohen, 2013, p. 75).
\end{abstract}

Gidenns (2010) e Lovins e Cohen (2013) já destacaram que as energias renováveis tornaram-se o caminho para uma economia com baixo teor de carbono com produção econômica limpa e eficiente via energias extraídas da movimentação dos ventos, das águas e do calor, processadas via tecnologias que aperfeiçoam-se cada vez mais pela busca da eficiência em gerar energia ao setor econômico, e com custos impactantes na implantação. Mas a longo prazo em comparação com o curto prazo, é considerado de baixo custo.

\begin{abstract}
A combinação de eficiência e energia renovável também está desencadeando uma nova economia energética de fabricação limpa e bons empregos nos Estados Unidos. Mais de 43 mil empresas americanas hoje estão fabricando e agregando tecnologias de energia renovável. Uma análise de 2006 do potencial desse mercado, "Renewable Energy Demand: A Study of California" [A Demanda da Energia Renovável: Pesquisa da Califórnia], descobriu que um programa de âmbito nacional para desenvolver energia renovável criaria mais de 85 mil empregos de alta tecnologia no setor industrial. Ele também levaria mais de 160 milhões de dólares em investimento para as empresas do setor industrial (Lovins e Cohen, 2013, p. 68).
\end{abstract}

O crescimento rápido das energias renováveis vem difundindo cada vez mais em empresas públicas e particulares, famílias e comunidades como um todo. Chegando a mostrar através de relatórios que o número total de países com políticas aumentaram demasiadamente para a implantação da energia renovável em 2015, informação mencionada no ANELL (2016, p. 8), "no final de 2015, pelo menos 173 países tinham metas para energias renováveis (sem incluir as INDCs) e estima-se que 146 países tinham políticas de apoio a energias renováveis em nível nacional ou estadual/provincial".

Um dos fatores que nortearam a expansão e atrelada ao crescimento com produção de energia suja para a mudança de energias limpas foi o acordo em Paris, através da Conferência das Partes (COP) em 2015 e conhecida como COP-21. Nessa convenção foi 
finalizada as negociações ao adotar o Acordo de Paris, na COP 22/CMA1 e constituiu a primeira sessão da Conferência das Partes no Acordo de Paris (CMA1), com isso os países comprometeram-se em usar mais energias renováveis no processo produtivo, auxiliando comunidades ao uso delas, como uma das formas de conter o aumento da temperatura média do planeta (Vieira, 2018), reavaliando os seus subsídios a combustíveis fósseis.

[...] 2015 foi um ano de acordos e anúncios inéditos e notáveis relacionados a energia renovável. Estes incluem compromissos do G7 e do G20 para acelerar o acesso a energias renováveis e promover a eficiência energética e a adoção pela Assembleia Geral da Organização das Nações Unidas de um Objetivo de Desenvolvimento Sustentável específico para Energia Sustentável para Todos (SDG 7) (ANELL, , 2016, p. 6).

Apesar da mobilização política pela expansão da energia renovável direcionada para uma nova economia energética, os investimentos em energias renováveis aumentaram em nível global, segundo ANELL (2016) os países em desenvolvimento como China, Índia e Brasil em 2015 comprometeram-se com um total de US $\$ 156$ bilhões (19\% a mais em comparação com 2014), os Estados Unidos, o investimento em energias renováveis (dominado amplamente pela energia solar) aumentou 19\%, para US\$ 44,1 bilhões, o maior aumento em dólares para o país desde 2011.

Conforme a ONU (2020), "o investimento global em energias renováveis atingiu 288,9 bilhões de dólares em 2018, superando o apoio financeiro à geração de energia a partir de combustíveis fósseis". Os dados ainda mostram que esse número não envolvem as hidrelétricas "acima de $50 \mathrm{MW}$, que registrou um adicional de 16 bilhões de dólares investidos - também abaixo de 2017, quando 40 bilhões de dólares foram direcionados ao setor". Além disso, a energia solar registrou o maior quantitativo monetário de investimento, com 139,7 bilhões de dólares em 2018, mostrando queda de $22 \%$. "O investimento em energia eólica aumentou 2\% em 2018, totalizando 134,1 bilhões de dólares. Os outros setores ficaram muito abaixo, embora o investimento em biomassa e energia a partir de resíduos tenha aumentado 54\%, para 8,7 bilhões de dólares".

\section{Metodologia}

A metodologia do estudo tem como técnica empregada a indireta com resultados diretos descritivos e explicativos do mercado de energias renováveis. 0 estudo indireto norteia para a pesquisa bibliográfica e documental. A bibliográfica com livros, artigos publicados e revistas acerca da temática, possibilitando a construção da fundamentação teórica com base no assunto.

Relacionado ao estudo bibliográfico a pesquisa documental possibilitou complementar com relatório da ANELL (2016) e do Balanço Energético Nacional (BEN, $2017,2018,2019,2020)$, que facultaram os resultados descritivos diretos com explicações construídas com o estudo exploratório basedo em dados secundários qualitativo e quantitativo.

O estudo direciona para uma análise da eficiência energetica no cenário brasileiro através de casos de energias renováveis executados no país. Para observar esse cenário a estatística utilizada é a descritiva simples com variáveis absolutas e relativas construídas através dos dados disponibilizados pelos Relatórios. 0 sistema de processamento de dados foi o Software Excel, que auxiliou na organização e construção de tabelas, figuras e gráficos para a análise acerca do objetivo proposto. 


\section{Resultados e discussão}

\section{O Brasil no mercado de energias renováveis}

No Brasil, a difusão na discussão e preocupação relacionado ao modelo de Desenvolvimento Sustentável se deu por ocasião da Conferência das Nações Unidas sobre Meio Ambiente e Desenvolvimento (CNUMAND-92), realizada no Rio de Janeiro em 1992. A Conferência resultou na aprovação de vários documentos principalmente na Agenda 21, que foi elaborado com base no problema de hoje, gerado pelo modelo de crescimento econômico acelerado de ontem, cujo objetivo da Conferência é de preparar o mundo para os desafios do próximo século, recomendando novas práticas sociais, econômicas, políticas e ambientais (Barbieri, 1997).

Os relatórios elaborados e a Agenda 21 possibilitaram a necessidade de organizar mudanças na geração de energias suja para energias limpas, para que ocorram reduções no aquecimento do planeta. Em cada país a matriz energética expande com o acerelamento do capitalismo e nela percebe-se a renovação de energias para as renováveis no setor produtivo e social.

O Balanço Energético Nacional (BEN) de 2019, ano base 2018, e 2020 ano base 2019, retratam que a repartição da oferta interna do Brasil em 2018 foi de 54,7\% de energia não renováveis, em 2019 reduziu para 53,9\%. Enquanto nos mesmos períodos a energia renovável aumentou passando de 45,3\% em 2018, para 46,1\% em 2019. Um cenário de expansão da energia renovável no país, gerada pela biomassa, hidráulica, solar, eólica, dentre outras, favorecendo mudanças na geração de energia com o auxílio de políticas governamentais.

A Figura 2 mostra a oferta interna de energia e a demanda de consumo final no Brasil, ilustrando o cenário nos ano de 2016 até 2019, percebe-se nas comparações dos anos que a média de energia ofertada é de 291,375 Mtep e a demanda é de 257,675 Mtep, com oscilações de perdas de transmissão de energias geradas no Brasil.

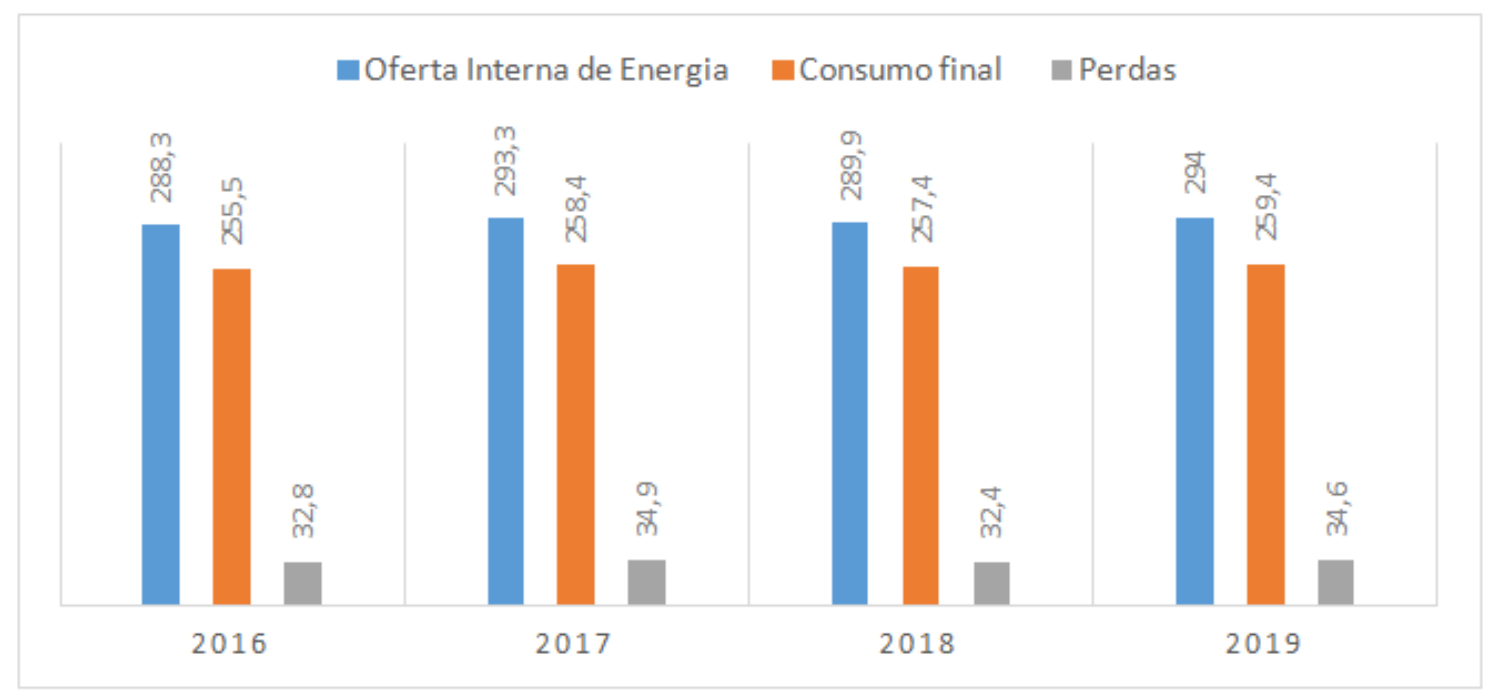

Figura 2. Oferta e Consumo de Energia no Brasil (Mtep). Fonte: BEN (2017, 2018, 2019, 2020).

Destacando com mais especificidade, os dados da Figura 2, a variação de aumento na oferta de energia de 2016 para 2017 foi de 1,3\% no Brasil, parte desse aumento adveio do gás natural $(6,7 \%)$ e energia eólica (26,5\%). Já a variação na oferta de 2017 a 2018 foi de decréscimo de 1,7\% ocasionado por alimentos e bebidas, não ferrosos e outros da 
metalurgia e rodoviário, além do gás natural, petróleo e derivados. Observando 2019 a variação foi registrada de acréscimo de 1,4\% em relação ao ano anterior, ocasionado pelas energias renováveis: eólica, solar, biomassa da cana e biodisel.

Observando o consumo final, na Figura 2, de 2016 a 2017 ocorreu um acréscimo de $1,2 \%$ devido ao setor de transporte e indústria, além do residencial também ter contribuido com $0,9 \%$. 0 consumo no transporte adveio do óleo dissel e gasolina e a indústria com carvão mineral, siderúrgico e lixívia para a produção de papel e celulase. 0 consumo final de 2017 e 2018 percebe-se um recuo de 1\%, provocado pela indústria advinda da produção do açúcar e não ferrosos e outros da metalurgia. Em 2019 o consumo maior foi seguido de aumento com veículos leves, com o etanol hidratado que ganhou participação em relação à gasolina automotiva, com $45 \%$ do consumo, contra $42 \% \mathrm{em}$ 2018. 0 álcool anidro aumentou em consumo (+3,3\%) em 2019, além disso o consumo residencial chegou a aumentar em 3,5\%.

Devido a geração de energia suja ter reduzido de 2017 para 2018 e aumentado a geração de energia limpa, isso resultou em reduções de dióxido de carbono no país, comprovada no BEN (2018, p. 9), que afirma que "em 2017, o total de emissões antrópicas associadas à matriz energética brasileira atingiu 435,8 milhões de toneladas de dióxido de carbono equivalente ( $\mathrm{Mt} \mathrm{CO}_{2}$-eq), sendo a maior parte (199,7 Mt CO2-eq) gerada no setor de transportes". Enquanto no relatório do BEN (2019, p. 10), "em 2018, o total de emissões antrópicas associadas à matriz energética brasileira atingiu 416,1 milhões de toneladas de dióxido de carbono equivalente ( $\mathrm{Mt} \mathrm{CO}_{2}$-eq), sendo a maior parte $(192,7 \mathrm{Mt}$ $\mathrm{CO}_{2}$-eq) gerada no setor de transportes". Os resultados elucidados mostram que a medida que o uso da enegia renovável aumenta no Brasil a emissão de dióxido de carbono reduziu em 4,5204\% e contribui para a redução do aquecimento do planeta.

As observações das energias renováveis no Brasil, na Figura 3 confirmam que as três fontes de energias que prevalecem no Brasil são: petróleo e derivados, gás natural e carvão mineral. Segundo Giddens (2010, p. 57) "petróleo, gás natural e carvão, as três fontes de energia que predominam no mundo, são todas combustíveis fósseis, produtores em larga escala de gases causadores do efeito estufa". Nesse âmbito de dependência faz-se necessário mudanças no fornecimento do tipo de energia para tornar muito mais limpo em geração de energia e percebe-se na figura reduções de enrgias advindas das três fontes principais no Brasil, de 2017 até 2019.

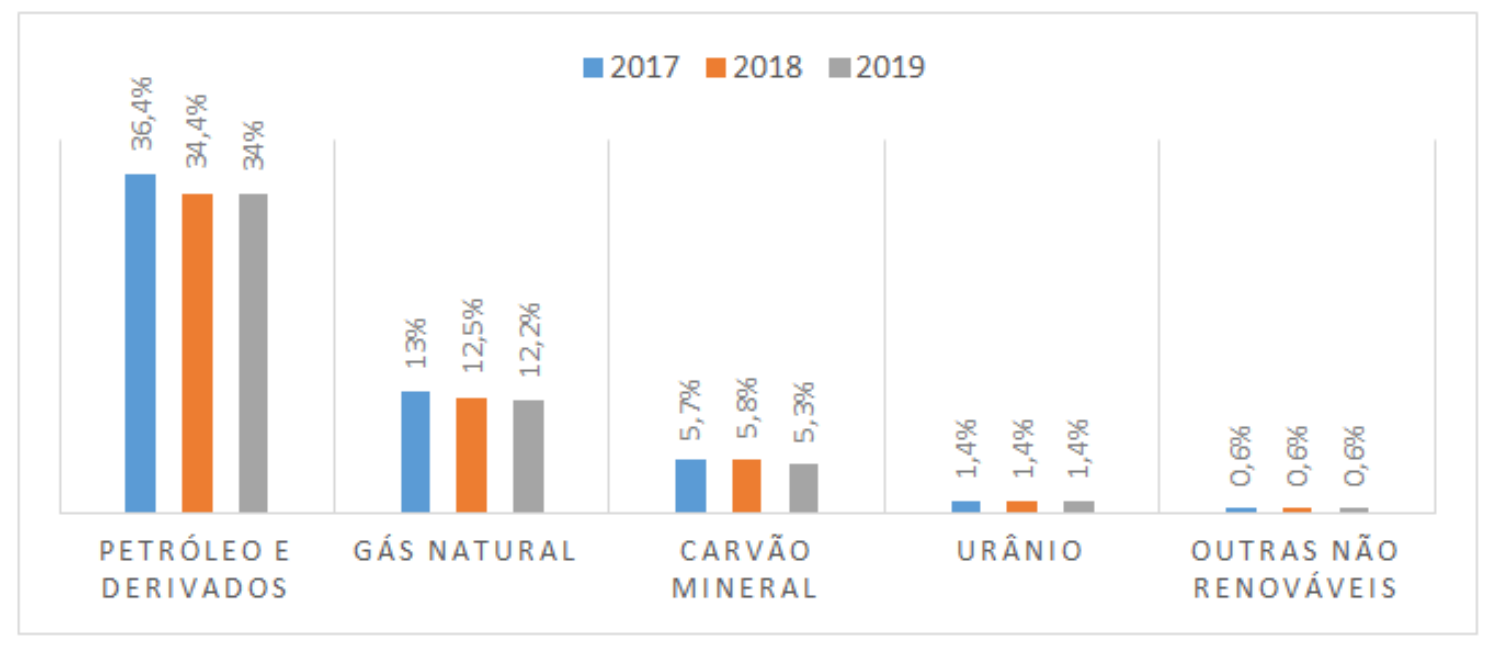

Figura 3. Energias não renováveis no Brasil. Fonte: $\operatorname{BEN}(2018,2019,2020)$. 
Com a predominância do petróleo e derivados no Brasil como fonte principal da energia não-renovável, alternativas começaram a ser implantadas na utilização do uso da energia renovável no país que em grande parte $(18 \%)$ vem da biomassa da cana e hidráulica (12,4\%), conforme Figura 4. Esse avanço advém das condições edafoclimáticas em que as usinas estão localizadas no cultivo da cana-de-açúcar e produtividade, assim como a geração de energia hidráulica, além disso as políticas governamentais auxiliaram no avanço da cogeração de energia da biomassa.

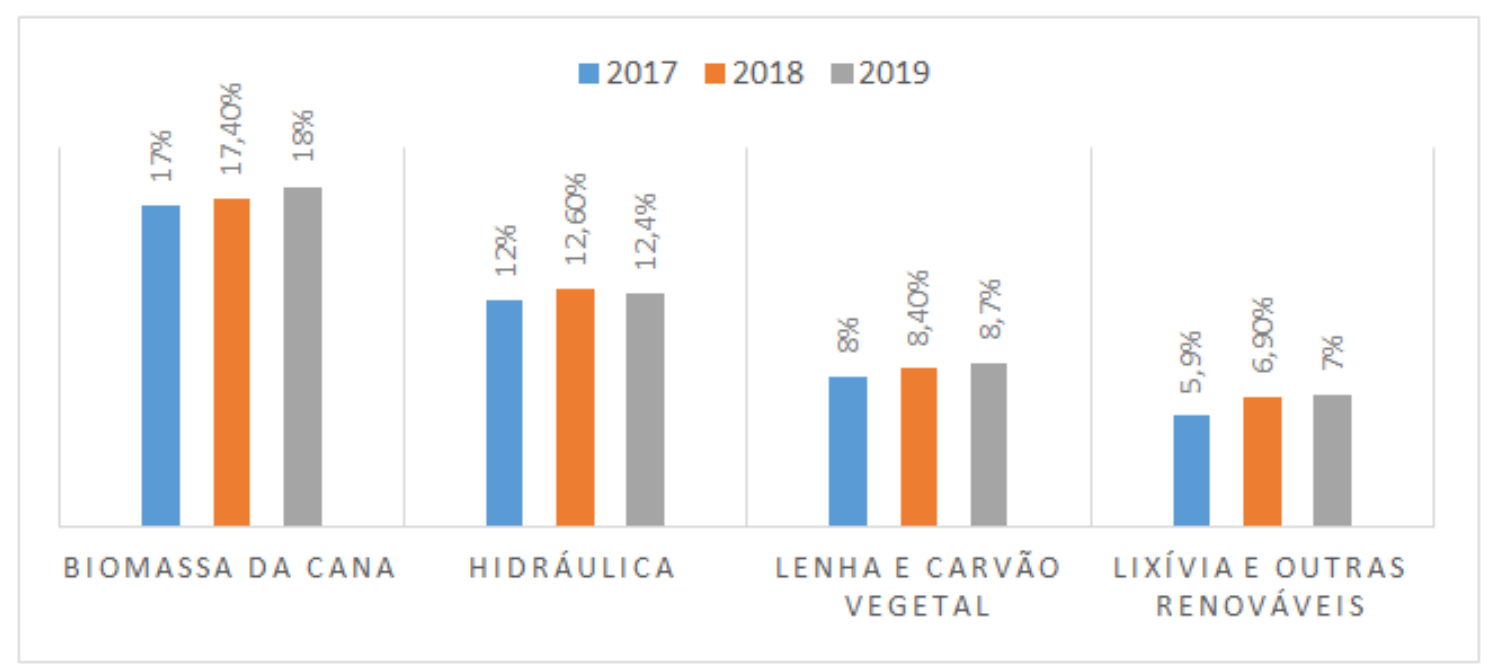

Figura 4. Energias renováveis no Brasil. Fonte: BEN $(2018,2019,2020)$.

Destacando com mais especificidade as energias renováveis, na tabela 2, apresentam variações de estudo na geração de energia de 2017/2018 no Brasil, que correspondem a resultados positivos de 3,4\% de energia renováveis, desse total gerado a energia solar sobressalta com 316,1\% de crescimento no país. Enquanto em 2018/2019 ocorreu $2,8 \%$ de variação em crescimento e a biomassa destaca-se em relação aos períodos anteriores por alcançar 5,5\% em crescimento.

Percebe-se na Tabela 2 que as energias não renováveis estão negativos em $2017 / 2018$ e apenas nos períodos de 2018/2019 ocorre um aumento em petróleo e derivados de $1,4 \%$, enquanto os demais chegam a obter valor nulo (0) com queda, confirmando que o Brasil vem passando por mudanças na fonte renovável de geração de energia.

A expansão da energia renovável no Brasil deve-se, também, à Resolução Normativa ANELL no 482/2012 (ANELL, 2012), que possibilitou ao consumidor gerar sua própria energia, mas compensando os seus créditos na conta de energia, além de possibilitar centrais geradoras de energias elétricas com potenciais instalados para as microgeração e minigeração. 
Tabela 2. Variação em crescimento de energias renováveis e não renováveis no Brasil (Mtep).

\begin{tabular}{|l|c|c|c|c|c|c|}
\hline \multicolumn{1}{|c|}{ Fonte (Mtep) } & $\mathbf{2 0 1 7}$ & $\mathbf{2 0 1 8}$ & $\mathbf{\Delta 2 0 1 8 / 2 0 1 7}$ & $\mathbf{2 0 1 8}$ & $\mathbf{2 0 1 9}$ & $\mathbf{\Delta 2 0 1 8 / 2 0 1 9}$ \\
\hline Renováveis & $\mathbf{1 2 6 , 2}$ & $\mathbf{1 3 0 , 5}$ & $\mathbf{3 , 4 \%}$ & $\mathbf{1 2 6 , 1 1 9}$ & $\mathbf{1 2 9 , 2 3 5}$ & $\mathbf{2 , 8} \%$ \\
\hline Energia hidráulica & 35 & 36,5 & $4,1 \%$ & 36,5 & 36,4 & $-0,3 \%$ \\
\hline Biomassa da cana & 49,8 & 50,1 & $0,7 \%$ & 50,1 & 52,8 & $5,5 \%$ \\
\hline Lenha e Carvão vegetal & 24 & 24,1 & $0,6 \%$ & 25,5 & 25,7 & $0,8 \%$ \\
\hline Eólica & 3,6 & 4,2 & $14,4 \%$ & 4,168 & 4,815 & $15,5 \%$ \\
\hline Solar outras & 0,072 & 0,298 & $316,1 \%$ & 0,298 & 0,572 & $92,5 \%$ \\
\hline $\begin{array}{l}\text { Lixívia e } \\
\text { renováveis }\end{array}$ & 13,8 & 15,4 & $11,8 \%$ & 9,553 & 8,948 & $6,2 \%$ \\
\hline Não renováveis & $\mathbf{1 6 7}$ & $\mathbf{1 5 7 , 9}$ & $\mathbf{- 5 , 5 \%}$ & $\mathbf{1 5 8}$ & $\mathbf{1 5 8 , 4}$ & $\mathbf{0 , 2} \%$ \\
\hline Petróleo e derivados & 106,3 & 99,3 & $-6,5 \%$ & 99,6 & 101,1 & $1,4 \%$ \\
\hline Gás natural & 37,9 & 35,9 & $-5,4 \%$ & 35,9 & 35,9 & $0,0 \%$ \\
\hline Carvão mineral & 16,8 & 16,6 & $-0,9 \%$ & 15,5 & 15,5 & $-5,7 \%$ \\
\hline Urânio (U308) & 4,2 & 4,2 & $-0,5 \%$ & 4,2 & 4,2 & $0,0 \%$ \\
\hline Outras não renováveis & 1,8 & 1,8 & $-0,1$ & 1,8 & 1,8 & $-3,7 \%$ \\
\hline
\end{tabular}

Fonte: $\operatorname{BEN}(2018,2019,2020)$.

A Resolução Normativa ANELL no 482/2012 (ANELL, 2012) possibilitou o favorecimento ao consumidor individual, que possa custear a instalação de unidades técnicas de geração de energia renovável, além de favorecer às empresas de um modo geral. E com o passar do tempo a Resolução Normativa ANELL no 482/2012 foi alterada e a diretoria da ANELL autorizou algumas melhorias com a Resolução Normativa ANELL no 687/2015 (ANELL, 2015), nos Módulos 1 e 3 dos Procedimentos de Distribuição que rege a alteração no prazo de validade dos créditos que passou de 36 para 60 meses.

\section{Conclusões}

A dinâmica do mercado capitalista mostra a necessidade da produção econômica devido a sua expansão em crescimento populacional que ao mesmo tempo possibilita a necessidade de um desenvolvimento social baseado no uso da energia, que data da primeira Revolução Industrial do século XVIII, através do petróleo, gás natural e carvão. As três fontes de energia que até o século atual ainda predominam no processo produtivo em alguns países, como o Brasil.

As consequências do excesso no uso das energias não renováveis despertaram inquietações em todo o planeta, gerando reuniões e conferências que foram realizadas com o propósito de despertar através de políticas públicas de cada Nação o compromisso de mudanças na geração de energias, através da implantação de tecnologias ambientais e com uso e geração de energias renováveis. Assim, estudos e pesquisas atreladas a ciência foi cada vez mais avançando para o surgimento de modernas máquinas, turbinas, placas e etc, para geração de energia renovável.

Investimentos aumentam nas particularidades de cada Nação, com o propósito de aumentar a geração de energias renováveis em substituição das não renováveis. Nesse contexto, o Brasil vem mostrando desempenho em avanços para essas mudanças de energias, apesar da redução de 54,7\% (2018) para 53,9\% (2019) das energias geradas não renováveis e com queda de variação de 5,5\% de 2018/2017 para 0,2\% de 2018/2019, com petróleo, gás natural, carvão e outros. E, 45,3\% vem de energia renovável em 2018 e em 2019 passa a ser de 46,1\%, com aumento de 3,4\% de 2018/2017 e 2,8\% de $2018 / 2019$, tendo biomassa da cana, hidráulica, solar, eólica, dentre outras alavancando o crescimento no Brasil. 0 investimento previsto do setor privado no Brasil é de 21,3 bilhões 
de reais para a energia solar até 2022 e $36 \%$ deve ser a parcela da energia solar na matriz energética em 2040, a hídrica chegou a 35\%.

Além da eficiência de energia renovável gerada pela sociedade e empresas em geral, o mercado energético brasileiro através das normas brasileiras da ANNEL também favorecem o consumidor individual que podem custear e abater na sua conta de energia os créditos gerados pela energia solar da residência.

As mudanças estão ocorrendo no Brasil advinda das Nações desenvolvidas. Todavia, faz-se necessária em todas as Nações para que o planeta possa dinâmizar o capitalismo sem a selvageria com a energia renovável, apesar dos países em desenvolvimento ter limitações em investimento para geração e cogeração de energias renováveis. É necessário viver com a leveza da produção econômica em crescimento sem a poluição, como também é possível com a redução do egoísmo advindo do capitalismo.

\section{Conflito de interesses}

A autora declara não haver conflito de interesses.

\section{Referências}

ANEEL - Agência Nacional de Energia Elétrica. Energias renováveis 2016: relatório da situação mundial. Brasília: ANEEL, 2016.

ANEEL - Agência Nacional de Energia Elétrica. Atlas de energia elétrica do Brasil. Brasília: ANEEL, 2008.

ANEEL - Agência Nacional de Energia Elétrica. Resolução Normativa ANEEL no 482, de 17 de abril de 2012. Disponível em: <http://www2.aneel.gov.br/cedoc/ ren2012482.pdf>. Acesso em: 22 set. 2019.

ANEEL - Agência Nacional de Energia Elétrica. Resolução Normativa ANEEL no 687, de 24 de novembro de 2015. Disponível em: <http://www2.aneel.gov.br/cedoc/ ren2015687.pdf>. Acesso em: 22 set. 2019.

Barbieri, J. C. Desenvolvimento e meio ambiente: as estratégias de mudanças da agenda 21. Petrópoles: Vozes, 1997.

BEN - Balanço Energético Nacional. Relatório síntese: ano base 2015. Rio de Janeiro: BEN, 2016.

BEN - Balanço Energético Nacional. Relatório síntese: ano base 2016. Rio de Janeiro: BEN, 2017.

BEN - Balanço Energético Nacional. Relatório síntese: ano base 2017. Rio de Janeiro: BEN, 2018.

BEN - Balanço Energético Nacional. Relatório síntese: ano base 2018. Rio de Janeiro: BEN, 2019.

BEN - Balanço Energético Nacional. Relatório síntese: ano base 2019. Rio de Janeiro: BEN, 2020.

Brum, A. J. 0 desenvolvimento econômico brasileiro. 30. ed. Petrópolis: Vozes, 2013.

Giddens, A. A política da mudança climática. Rio de Janeiro: Zahar, 2010.

Lovins, L. H.; Cohen, B. Capitalismo climático: liderança inovadora para um crescimento econômico sustentável. São Paulo: Cultrix, 2013. 
Oliveira, E. A. A técnica, a techné e a tecnologia. Itinerarius Reflectionis, v. 2, n. 5, p. 1-13, 2008. https://doi.org/10.5216/rir.v2i5.510

ONU - Nações Unidas Brasil. Investimentos em energias renováveis supera o de combustíveis fósseis em 2018 no Mundo. Disponível em: $<$ https://nacoesunidas.org/investimento-em-energias-renovaveis-supera-o-decombustiveis-fosseis-em-2018-no-mundo/>. Acesso em: 04 maio 2020.

Pires, M. C. Economia brasileira: da colônia ao governo Lula. São Paulo: Saraiva, 2010.

REN21 - Renewables 2020. Global Status Report. REN21, 2020. Disponível em: <https://www.ren21.net/reports/global-status-report/>. Acesso em: 20 jul. 2020.

Vieira, A. C. F. A polidez climática através das conferências das partes: ensaio político. Revista Brasileira de Gestão Ambiental e Sustentabilidade, v. 5, n. 9, p. 75-87, 2018. https://doi.org/10.21438/rbgas.050905

Informação da Licença: Este é um artigo Open Access distribuído sob os termos da Licença Creative Commons Attribution, que permite uso irrestrito, distribuição e reprodução em qualquer meio, desde que a obra original seja devidamente citada. 